\title{
Prevalence of Risk Factors for Denture Stomatitis in Complete Denture Wearers
}

Laura Lourenço Morel ${ }^{1}$, Anna Paula da Rosa Possebon², Fernanda Faot ${ }^{1}$, Luciana de Rezende Pinto ${ }^{1, *}$

1 Department of Restorative Dentistry, School of Dentistry, Federal University of Pelotas, Pelotas, RS, Brazil.

${ }^{2}$ Graduate Program in Dentistry, School of Dentistry, Federal University of Pelotas, Pelotas, RS, Brazil.
Corresponding author: Luciana de Rezende Pinto Department of Restorative Dentistry, School of Dentistry, Federal University of Pelotas, Gonçalveschaves St 457, Center, Pelotas 96015560, RS, Brazil. Fax: +55 5332256741 .

E-mail address: lucianaderezende@ yahoo.com.br

Received: September 22, 2018 Accepted: January 01, 2019
Aim: The prevalence of denture stomatitis and the relationship with its risk factors was evaluated via secondary data from 62 complete denture (CD) wearers, between 2015 and 2017. Methods: The data was stored in an Excel database and was analyzed using the statistics software STATA/SE12.0. A descriptive analysis was performed taking into account a categorization of the clinical variables according to risk factor in 4 domains: $C D$ usage, systemic health, hygiene habits, and usage habits. The association amongst the denture stomatitis and risk factors variables was tested by the Chi-square test and the results were statistically significant at $p$-values $<0.05$. Results: The CD wearers participants were composed by a majority of elderly (80.64\%) and women (72.78\%); with $45.16 \%$ having been using the current denture for more than 10 years and another $74.19 \%$ related a continuous usage. Diabetes and hypertension were related by $83.87 \%$ and $67.74 \%$, respectively, with $87.10 \%$ using medication. Although $75.80 \%$ reported cleaning their dentures 3 times per day or more, and $59.68 \%$ considered their oral hygiene very good, $50 \%$ of the complete dentures showed dirtiness and clinical signs of Denture Stomatitis were present in $30.64 \%$ of the patients. Despite of the evaluated sample shows many risk factors for the development of the disease, an association between the variables was not observed. Conclusion: Considering the high prevalence of the disease in the studied sample, preventive and educational measures on denture usage and hygiene must be reinforced in order to maintain the oral health of the edentulous patients.

Keywords: Denture, complete. Stomatitis, denture. Risk factors. 


\section{Introduction}

In Brazil, there is a high prevalence of dental loss and edentulism, especially on elderly people, when compared to other age groups ${ }^{1}$. Nearly $62.6 \%$ of the elderly population in Brazil wears the upper complete denture (CD) and $40.3 \%$ still shows a need to use the $\mathrm{CD}^{2}$. Complete denture pair promotes the huge positive impact of the CD wearers, mainly in elders, is well-documented, mainly because stable and retentive CD improve masticatory function, phonation, muscular and articular comfort, aesthetics, socialization, and self-esteem ${ }^{3}$.

Around $70 \%$ of the CD wearers develop Chronic Erythematous Candidiasis, also known as "Denture Stomatitis"4. This pathology is characterized by a fungal infection that triggers a chronic inflammation on the mucous membrane that covers the hard palate, caused by the pathological growth of the Candida albicans. Findings from Bianchi et al. ${ }^{5}$ (2016), showed that $83.3 \%$ of the CD wearers show C. albicans in their saliva samples. One well known contribution to this scenario is the fact that CD bases are fabricated using polymethylmethacrylate still present problems related to their technical processing mainly related to finishing and polishing. As result, their surfaces are microporous, which favors the adhesion of microorganisms that colonize the surface and the interior of the acrylic ${ }^{6}$. Thus, the presence of fungi from the Candida sp associated to other microorganisms that form the denture biofilm, is one of the main risk factors in order to develop Denture Stomatitis. In addition, long periods of usage or the continual use of the $\mathrm{CD}$, associated to trauma and faulty oral and denture hygiene, predispose the development of the disease. Besides that, factors related to the individuals, such as the systemic health condition, presence of chronical diseases, diet, hormonal oscillations, immunodeficiency, saliva quality and quantity, have a direct influence on the risks of Denture Stomatitis ${ }^{7}$.

In order to prevent the disease, CD wearers must be oriented to make a constant evaluation of the oral cavity and the CD status, as well as being always attentive to the adaptation of the CD to the oral tissues, and also their usage habits and care ${ }^{8}$. It is also indispensable that the cleaning methods are followed correctly by the patients. The combination of mechanical and chemical cleaning methods shows efficiency, as long as the CD wearer knows how to proceed a correct disinfection?. The regular hygiene of the CD guarantees the efficient removal of the formed biofilm, as well as a significant variation of the dentures microbiota through the different types of materials of the dentures hygien $e^{10}$.

The objective of this study is to evaluate the prevalence of Denture Stomatitis in CD wearers and to investigate the association with risk factors as time of upper complete denture usage, hypertension and diabetes presence, use of medications, hygiene habits and usage habits. The tested null hypothesis indicates that there is no relationship between the risk factors of the Denture Stomatitis and the development of this pathology.

\section{Materials and Methods}

The prevalence of the risk factors for Denture Stomatitis was evaluated through secondary data from the medical records of 62 patients, superior CD wearers, treated 
at the Complete Denture Clinic of Dentistry School - Federal University of Pelotas, from 2015 to 2017. Individuals who agreed to participate, signed a written informed consent based on the Declaration of Helsinki. Data referring to age, time of denture usage, systemic health, hygiene habits, and denture use was collected. Information on the presence of signals for denture stomatitis, and visible dirt at the internal surface of the denture were also evaluated. The attendants were classified according to the presence of Denture Stomatitis and its severity according to the classification from Newton ${ }^{11}$ (1962). Clinically, the Denture Stomatitis can be classified according to the gravity of its clinical signs: type I (punctate hyperemia): characterized by the hyperemia of the ducts of the minor palatine salivary glands; which confers a erythematous punctate aspect, and can occupy disperse areas or small ones localized on the palate; type II (diffuse): shows a smooth and atrophic mucosa, with an erythematous aspect on all of the area below the denture; type III (granular): is frequently associated to the suction chamber, ailing the central region of the palate with a nodular and rough clinical appearance of the mucosa ${ }^{11}$.

The variables related to the risk factors for the development of Denture Stomatitis collected from the anamnesis questionnaire were grouped in domains: CD usage (age, gender, time of upper complete denture usage), systemic health (hypertension and diabetes presence, use of medications), hygiene habits (frequency of the CD and oral cavity cleaning and the products used for it, self-perception on the CD and oral cavity cleaning, presence of dirt at the internal surface of the upper $C D$, usage habits (continuous usage of the denture and frequency of continual usage). The data collected were stored in an Excel (Microsoft Office 2007) database. The variables were analyzed using the STATA/SE 12.0 statistical software and described according to the distribution of the frequency. The association amongst the variables "presence of denture stomatitis" and "risk factors" was tested by the Chi-square test. Values of p lower than 0.05 were considered statistically significant.

\section{RESULTS}

The "CD usage" domain, composed by the characterization of the sample according to the distribution through gender, age and time of upper CD usage showed a majority of women (72.78\%) and elderly above 60 years of age (80.64\%). Twenty-eight patients $(45.16 \%)$ used the same upper CD for more than 10 years (Table 1). The "systemic health" domain showed medication usage by $87.10 \%$ of the sample, diabetes for $16.13 \%$ and hypertension for $32,26 \%$ (Table 2).

From the 62 evaluated patients, 19 (30.65\%) showed clinical signs of Denture Stomatitis, with 14 (22.58\%) classified as Type I, 4 (6.5\%) as Type II, and 1 (1.61\%) as Type III. In relation to the "hygiene habits" domain, $75.80 \%$ and $64.51 \%$ of the patients answered that they cleaned their $\mathrm{CD}$ and oral cavity three times per day or more, respectively. The most used products for the denture hygiene were the hard toothbrush $(38.71 \%)$ and neutral dental paste (93.55\%). The use of sodium hypochlorite diluted in water and sodium bicarbonate was reported by $35.48 \%$ and $22.58 \%$ of the sample, respectively. Although $59.68 \%$ of the evaluated patients considered their oral and denture hygiene as very good, it was possible to note the presence of visible biofilm at the internal portion of the upper complete dentures in $50 \%$ of the evaluations (Table 3 ). On 
Table 1. Distribution of the sample according to the upper complete denture usage domain.

\begin{tabular}{lccc}
\hline & Upper Complete Denture Usage & $n$ & $\%$ \\
\hline \multirow{2}{*}{ Age } & $<60$ years old & 12 & $19.36 \%$ \\
\cline { 2 - 4 } & $>60$ years old & 50 & $80.64 \%$ \\
\hline \multirow{2}{*}{ Gender } & Woman & 45 & $72.78 \%$ \\
\hline \multirow{2}{*}{ Time of use } & Man & 17 & $27.22 \%$ \\
\cline { 2 - 4 } & $<10$ years of use & 34 & $54.83 \%$ \\
\hline
\end{tabular}

Table 2. Distribution of the sample according to the systemic health domain.

\begin{tabular}{|c|c|c|c|}
\hline \multicolumn{2}{|c|}{ Systemic Health } & \multirow{2}{*}{$\frac{n}{20}$} & \multirow{2}{*}{$\begin{array}{c}\% \\
32.26 \%\end{array}$} \\
\hline Hunertencinn & Yes & & \\
\hline 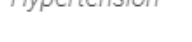 & No & 42 & $67.74 \%$ \\
\hline \multirow{2}{*}{ Diabetes } & Yes & 10 & $16.13 \%$ \\
\hline & No & 52 & $83.87 \%$ \\
\hline \multirow{2}{*}{ Medication use } & Yes & 54 & $87.10 \%$ \\
\hline & No & 8 & $12.90 \%$ \\
\hline
\end{tabular}

Table 3. Distribution of the sample according to the hygiene habits domain.

\begin{tabular}{|c|c|c|c|}
\hline & Hygiene Habits & $n$ & $\%$ \\
\hline \multirow{4}{*}{$\begin{array}{l}\text { Daily frequency of } \\
\text { denture cleaning }\end{array}$} & 1 time & 2 & $3.23 \%$ \\
\hline & 2 times & 13 & $20.97 \%$ \\
\hline & 3 times or more & 47 & $75.80 \%$ \\
\hline & Does not do & 5 & $8.06 \%$ \\
\hline \multirow{4}{*}{$\begin{array}{l}\text { Daily frequency of oral } \\
\text { cavity hygiene }\end{array}$} & 1 time & 7 & $11.29 \%$ \\
\hline & 2 times & 10 & $16.13 \%$ \\
\hline & 3 times or more & 40 & $64.51 \%$ \\
\hline & Does not do & 5 & $8.06 \%$ \\
\hline \multirow{4}{*}{$\begin{array}{l}\text { Products used for } \\
\text { hygienization }\end{array}$} & Hard bristle toothbrush & 24 & $38.71 \%$ \\
\hline & Neutral dental paste & 58 & $93.55 \%$ \\
\hline & Sodium Hypochlorite diluted in water & 22 & $35.48 \%$ \\
\hline & Sodium Bicarbonate & 14 & $22.58 \%$ \\
\hline \multirow{3}{*}{$\begin{array}{l}\text { Self-perception of the } \\
\text { denture hygiene }\end{array}$} & Very good & 5 & $8.06 \%$ \\
\hline & Good & 37 & $59.68 \%$ \\
\hline & Average or bad & 20 & $32.25 \%$ \\
\hline \multirow{2}{*}{$\begin{array}{l}\text { Visible dirt at the } \\
\text { denture }\end{array}$} & Yes & 31 & $50 \%$ \\
\hline & No & 31 & $50 \%$ \\
\hline
\end{tabular}

the "usage habits" domain, $74.19 \%$ uses the denture continuously; with $66.13 \%$ using it at all times (Table 4). The association test did not verified a significant statistical difference amongst the presence of clinical signs of Denture Stomatitis and the vari- 
Table 4. Distribution of the sample according to the upper complete denture usage habits.

\begin{tabular}{lccc}
\hline Usage Habits & & $\mathbf{n}$ & $\%$ \\
\hline \multirow{2}{*}{ Continuous use } & Yes & 46 & $74.19 \%$ \\
\cline { 2 - 4 } & No & 16 & $25.81 \%$ \\
\hline \multirow{2}{*}{ Frequency of continuous use } & 1 to 2 times per week & 2 & $3 ., 22 \%$ \\
\cline { 2 - 4 } & 3 to 4 times per week & 3 & $4.84 \%$ \\
\cline { 2 - 4 } & 5 to 6 times per week & 41 & $66.13 \%$ \\
\hline
\end{tabular}

ables of each of the tested domains (complete denture usage, systemic health, usage and hygiene habits), thus, the null hypothesis of the study was accepted.

\section{DISCUSSION}

According to data from the National Oral Health Research from 2010, Brazil presents up to $54 \%$ of fully edentulous people ${ }^{2}$. Cardoso et al. ${ }^{12}(2016)$, predicts an increase in edentulism in the next few years for people between 65 and 74 years old, that, according to Azevedo et al. $^{3}$ (2015), is considered a natural consequence of aging. Besides that, a study by Peres et al. ${ }^{1}$ (2013) showed that the prevalence of edentulism was associated with low income and schooling. In spite of that, there is no statistical association between aging and the presence of Denture Stomatitis ${ }^{13}$. The present study agrees with the findings from Tay et al. ${ }^{13}$ (2014), on the absence of correlation, and also on the prevalence of a sample above 60 years old.

From a literature revision that focuses on the use of CD in Brazil, it was observed that women present a higher prevalence of edentulism and use of upper $\mathrm{CD}^{1}$. It is also important to highlight that women seek dental health care with a higher frequency than men, for self-care reasons which are more frequent on their gender ${ }^{14}$. The results of the present study agree with those ones, pointing a prevalence of over than $70 \%$ of women that are users of complete denture.

On the prevalence of the Denture Stomatitis, female gender is still the majority, although the difference is not significant when compared to their male counterparts, with $58.3 \%$ and $41.3 \%$, respectively ${ }^{13}$. Many systemic diseases, such as leukemia, AIDS, autoimmune diseases, may directly interfere on the oral cavity ${ }^{5}$. On the systemic health and its association with the presence of Denture Stomatitis, a well-defined relationship may be observed between the hyposalivation from the diabetes and the clinical signs of the disease ${ }^{15}$, however, the association between the diabetes and the development of Denture Stomatitis was not found in the study by Peric et al. ${ }^{16}$ (2018). According to those authors, that result is justified due to the reduced number of people on the studied sample, which does not count as being representative for the whole population. Chopde et al. ${ }^{17}$ (2012), points out a relationship between hypertension, the use of medications, and diabetes with the development of Denture Stomatitis. In the sample of the present work, almost $90 \%$ of the patients made a systemic use of medications, and more than $30 \%$ suffered from hypertension. A total of $16.13 \%$ presented diabetes.

For the hygiene habits of the patients with upper $C D$, poor cleaning of the mouth and the denture is the predisposing local factor for the disease ${ }^{18}$. Besides that, the 
patients present a limited knowledge on oral and denture hygiene ${ }^{19}$. It is indispensable that the cleaning methods are made correctly by the CD wearer. The denture brushing is the mechanical method that shows success on the dislocation of the biofilm, although the usage of chemical products for denture immersion is still extremely important for an efficient reduction of the Candida albicans growth ${ }^{20}$. The regular hygiene of the dentures is needed in order to ensure an efficient removal of the formed biofilm, as well as a significant variation of the dentures microbiota by the different types of materials of the denture hygiene ${ }^{10}$. Souza et al. ${ }^{21}(2017)$ points out that the brushing of the palate may influence in the reduction of the inflammation, without the need for antifungals. Less than $50 \%$ of the sample of the present study cleans their CD at least 3 times a day. Furthermore, visible dirt could be perceived in half of the total internal surfaces of the upper complete dentures, which can be related to the unfamiliarity with methods and materials indicated for hygiene, as well as with the frequency with which they should do it. Difficulties related to advanced age, such as impaired vision and motor limitations also contribute for a poor hygiene of the dentures. Instructions in order to adopting a daily routine for denture hygiene, both mechanical and the immersion in chemical products, is essential in order to secure the biofilm the oral and denture biofilm²2.

The CD usage habits may influence the development of the Denture Stomatitis, as well as its type according to the Newton classification. Its highest prevalence, with $70 \%$, was found in CD with 10 years of usage ${ }^{13}$. In contrast, the study by Naik and Pai et al. ${ }^{18}$ (2011) considers that the age of the denture is no significantly responsible by the intensity of the palate inflammation, as well as the CD infection, although older upper CD show a greater quantity of Candida albicans for patients with Denture Stomatitis. According to Coelho et al. ${ }^{23}$ (2004), a big part of the patients with CD uses the same on for more than 20 years. In addition, Peracini et al. ${ }^{19}$ (2010) highlighted that approximately $25 \%$ of the patients use the same upper CD for an even longer time period. The present study verified that more than $45.16 \%$ of the patients use the same upper CD for more than 10 years. It should be pointed out that older dentures are harder to clean due to a tendency for porosity in their bases, which can contribute for the emergence of the disease ${ }^{16}$.

The results of the present study also agree with Aoun and Bereberi24 (2017) and GualVáques et $a{ }^{25}$ (2017) on the absence of association between the presence of Denture Stomatitis and the age of the denture users. Bianchi et al. ${ }^{5}(2016)$ also found the absence of association between diabetes and Denture Stomatitis. Although no association was found between hygiene habits and the presence of the studied disease, the specialized literature is unanimous avouching it. Some studies point out different results from this one, confirming an association between the presence of Denture Stomatitis and its risk factors, but only with more numerous samples, $5,24,26$. The sample in the present study is composed by only 62 individuals and can be considered a limiting factor, even though it shows that $30.65 \%$ of the CD wearers have clinical signs of Denture Stomatitis. It is also possible that the lack of a microbiologic analysis in order to diagnose the disease influenced the results of this work, since it is known that the presence of the Candida spp fungus, especially the Candida albicans is considered a main etiological factor for that pathology ${ }^{4}$. 
In conclusion, the prevalence of Denture Stomatitis in the studied fully edentulous participants is high and although no association with its risk factors was found. Preventive and educational measures for oral health in elderly, stimulating the correct hygiene of the denture and the oral cavity, should be a routine among professionals. Patients that use dentures must do maintenance of their dentures in order to preserve oral health.

\section{REFERENCES}

1. Peres MA, Barbato PR, Reis SCGB, Freitas CHSDM, Antunes JLF. Tooth loss in Brazil: Analysis of the 2010 Brazilian oral health survey. Rev Saude Publica. 2013 Jun;47(3):78-89. doi:10.1590/S0034-8910.2013047004226.

2. Azevedo JS, Azevedo MS, Oliveira LJC de, Correa MB, Demarco FF. [Uso e necessidade de prótese dentária em idosos brasileiros segundo a Pesquisa Nacional de Saúde Bucal (SBBrasil 2010): prevalências e fatores associados. Cad Saude Publica. 2017 Aug;33(8):1-12. doi: 10.1590/0102-311x00054016

3. Azevedo MS, Correa MB, Azevedo JS, Demarco FF. Dental prosthesis use and/or need impacting the oral health-related quality of life in Brazilian adults and elders: Results from a National Survey. J Dent. 2015 Dec;43(12):1436-41. doi:10.1016/j.jdent.2015.10.016.

4. Aguayo S, Marshall H, Pratten J, et al. Early Adhesion of Candida albicans onto Dental Acrylic Surfaces. J Dent Res. 2017 Jul;96(8):917-23. doi:10.1177/0022034517706354.

5. Bianchi C, Bianchi H, Tadano T, Paula C, Hoffmann-Santos H, Leite Jr D, Hahn R. Factors related to oral candidiasis in elderly users and non-users of removable dental prostheses. Rev Inst Med Trop Sao Paulo. 2016;58:17. doi: 10.1590/S1678-9946201658017.

6. Prakash B, Shekar M, Maiti B, Karunasagar I, Padiyath S. Prevalence of Candida spp. among healthy denture and nondenture wearers with respect to hygiene and age. J Indian Prosthodont Soc. 2015 Jan-Mar; 15(1):29-32. doi:10.4103/0972-4052.155041.

7. Mujica V, Rivera H, Carrero M. Prevalence of oral soft tissue lesions in an elderly venezuelan population. Med Oral Patol Oral Cir Bucal. 2008 May; 13(5):E270-4.

8. Gonçalves L, Neto D, Bonan R, Carlo H, Batista A. Higienização de Próteses Totais e Parciais Removíveis. Rev. Bra. Ciências da Saúde. 2011 Jan-Mar; 15(1):87-94. doi: 10.4034/RBCS.2011.15.01.13.

9. Cruz PC, Andrade IM de, Peracini A, et al. The effectiveness of chemical denture cleansers and ultrasonic device in biofilm removal from complete dentures. J Appl Oral Sci. 2011 Nov-Dec; 19(6):668-73. doi:10.1590/S1678-77572011000600021.

10. Ramage G, Zalewska A, Cameron DA, Sherry L, Murray C, Finnegan M, Loewy Z, Jagger D. A Comparative In Vitro Study of Two Denture Cleaning Techniques as an Effective Strategy for Inhibiting Candida albicans Biofilms on Denture Surfaces and Reducing Inflammation. 2012 Oct;21(7):516-22. doi:10.1111/j.1532-849X.2012.00865.x.

11. Newton AV. Denture sore mouth: a possible etiology. Br Dent J. 1962; 112: 357-60.

12. Cardoso M, Balducci I, Telles D de M, Lourenço EJV, Nogueira Júnior L. Edentulism in Brazil: trends, projections and expectations until 2040. Cien Saude Colet. 2016 Apr;21(4):1239-46. doi:10.1590/1413-81232015214.13672015.

13. Tay LY, Herrera DR, Brenda P, Santos FA, Janaina H. Identification of Candida Spp . In Patients with Denture Stomatitis : Relationship with Gender, Age, Time of Denture use and Newton's Classification. J Dent Appl. 2014 May-Jun;1(3):46-50. 
14. Machado LP, Camargo MB, Jeronymo JC, Bas- tos GA. Regular use of dental services among adults and older adults in a vulnerable region in Southern Brazil. Rev Saúde Pública 2012 Jun;46(3):526-33. doi: 10.1590/S0034-89102012000300015.

15. Yamashita J, Moura-Grec P, Capelari M, Sales-Peres A, Sales-Peres S. Manifestações bucais em pacientes portadores de Diabetes Mellitus: uma revisão sistemática. Rev Odontol Unesp. 2013 May-Jun; 42(3):211-20.

16. Perić M, Živković R, Lemić AM, Radunović M, Miličić B, Arsenijević VA. The severity of denture stomatitis as related to risk factors and different candida spp. Oral Surg Oral Med Oral Pathol Oral Radiol. 2018 Mar;126(1):41-7. doi:10.1016/j.0000.2018.03.003.

17. Chopde N, Jawale B, Pharande A, Chaudhari L, Hiremath V, Redasani R. Microbial colonization and their relation with potential cofactors in patients with denture stomatitis. J Contemp Dent Pract. 2012 Jul-Aug; 13(4):456-9. doi:10.5005/jp-journals-10024-1168.

18. Naik AV, Pai RC. A study of factors contributing to denture stomatitis in a North Indian community. Int J Dent. 2011. doi:10.1155/2011/589064. Available from: https://www.hindawi.com/journals/ ijd/2011/589064.

19. Peracini A, Andrade IM, Freitas H, Paranhos O, Helena C, Souza RF. Behaviors and Hygiene Habits of Complete Denture Wearers. Braz Dent J 2010 May-Jun;21(3):247-52. doi:10.1590/S0103-64402010000300013.

20. Lee HE, Li CY, Chang HW, Yang YH, Wu JH. Effects of different denture cleaning methods to remove Candida albicans from acrylic resin denture based material. J Dent Sci 2011 Dec;6(4):216-20. doi:10.1016/j.jds.2011.09.006.

21. Souza RF De, Khiyani MF, Chaves CAL, Feine J, Barbeau J, Fuentes R, Borie E, Crizostomo I, SilviaLovato C, Rompre P, Emami E. Improving practice guidelines for the treatment of denture-related erythematous stomatitis : a study protocol for a randomized controlled trial. Trials 2017. doi:10.1186/ s13063-017-1947-y. Available from: https://trialsjournal.biomedcentral.com/track/pdf/10.1186/ s13063-017-1947-y.

22. Neppelenbroek KH. The importance of daily removal of the denture biofilm for oral and systemic diseases prevention. J Appl Oral Sci. 2015 Nov-Dec;23(6):547-8. doi:10.1590/1678-77572015ed006.

23. Coelho CM, Sousa YT, Daré AM. Denture-related oral mucosal lesions in a Brazilian school of dentistry. J Oral Rehabilit. 2004 Fev; 31(2):135-9. doi.org/10.1111/j.1365-2842.2004.01115.x.

24. Aoun G, Berberi A. Prevalence of Chronic Erythematous Candidiasis in Lebanese Denture Wearers : a Clinico-microbiological Study. Mater Sociomed. 2017 Mar; 29(1): 26-29. doi:10.5455/msm.2017.29.26-29.

25. Gual-Vaqués P, Jané-Salas E, Egido-Moreno S, Ayuso-Montero R, Marí-Roig A, López-López J. Inflammatory papillary hyperplasia: A systematic review. Med Oral Patol Oral Cir Bucal. Jan 2017;22(1):36-42. doi:10.4317/medoral.21405.

26. Moosazadeh M, Akbari M, Tabrizi R, Ghorbani A, Golkari A, Banakar M, Sekhavati E, Kavari SH, lankarani KB. Denture Stomatitis and Candida Albicans in Iranian Population: A Systematic Review and Meta-Analysis. J Dent Shiraz Univ Med Sci. 2016 Sep;17(3 Suppl): 283-92. 